This item was submitted to Loughborough's Research Repository by the author.

Items in Figshare are protected by copyright, with all rights reserved, unless otherwise indicated.

\title{
Fabrication of biodegradable poly(lactic acid) particles in flow focusing glass capillary devices
}

PLEASE CITE THE PUBLISHED VERSION

http://www.constableandsmith.com/UKColloids2011/conference.htm

LICENCE

CC BY-NC-ND 4.0

\section{REPOSITORY RECORD}

Vladisavljevic, Goran T., Wynter J. Duncanson, Ho Cheung Shum, and David A. Weitz. 2012. "Fabrication of Biodegradable Poly(lactic Acid) Particles in Flow Focusing Glass Capillary Devices”. figshare.

https://hdl.handle.net/2134/10623. 
This item was submitted to Loughborough's Institutional Repository (https://dspace.lboro.ac.uk/) by the author and is made available under the following Creative Commons Licence conditions.

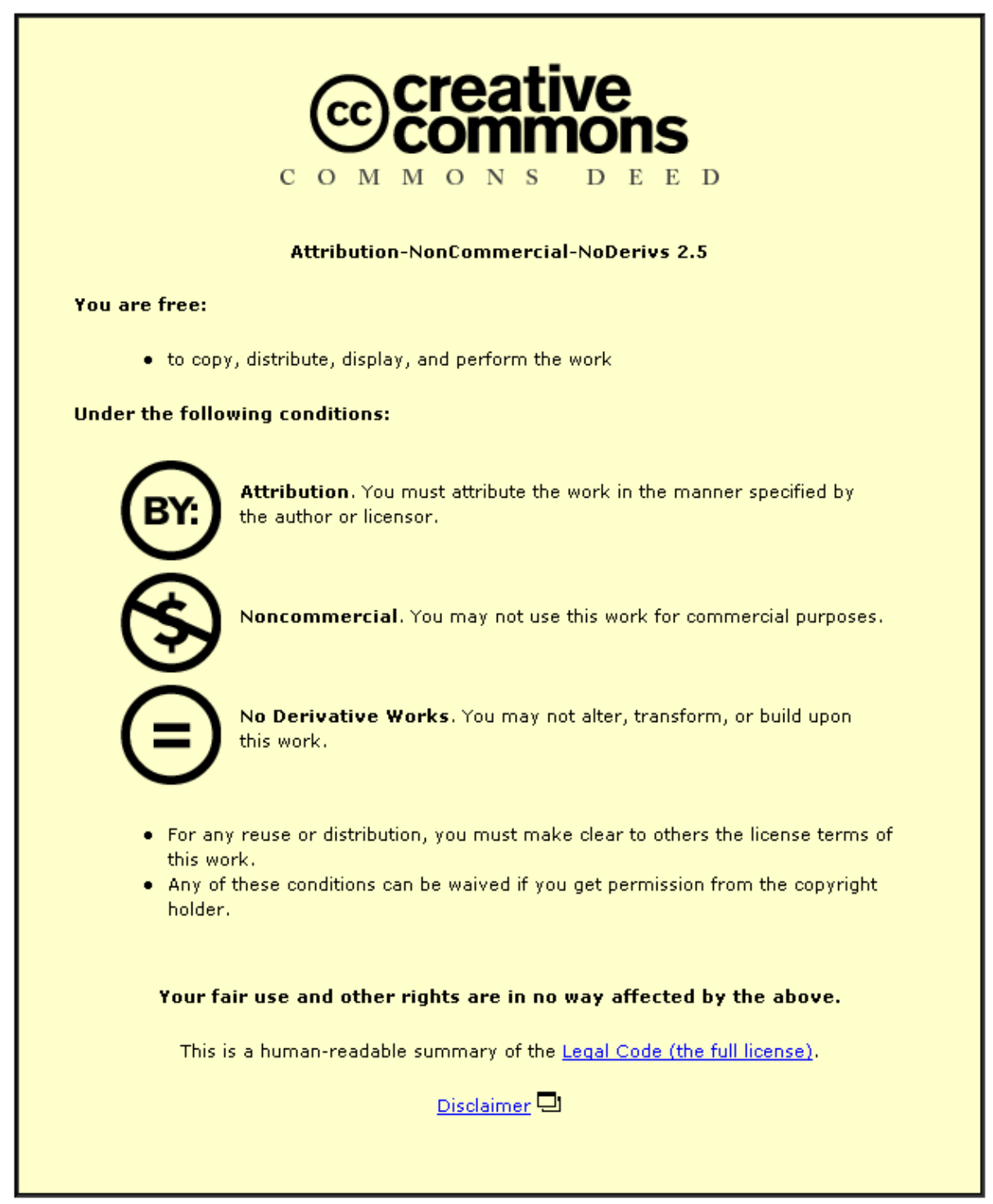

For the full text of this licence, please go to: http://creativecommons.org/licenses/by-nc-nd/2.5/ 


\section{Fabrication of biodegradable poly(lactic acid) particles in flow focusing glass capillary devices}

\section{[G.T. Vladisavljević ${ }^{1}$, W.J. Duncanson ${ }^{2}$, H.C. Shum ${ }^{3}$, D.A. Weitz ${ }^{2}$ ]} ${ }^{1}$ Department of Chemical Engineering, Loughborough University, Loughborough, LE11 3TU, UK; ${ }^{2}$ Department of Physics, Harvard University, Cambridge, MA 02138, USA; ${ }^{3}$ Department of Mechanical Engineering, University of Hong Kong, Hong Kong.

\section{G.Vladisavljevic@lboro.ac.uk}

Abstract:

Poly(dl-lactic acid) (PLA) particles with a diameter in the range from 12 to $100 \mu \mathrm{m}$ were fabricated in flow focusing glass capillary devices shown in Figure 1. The disperse phase was $5 \%(\mathrm{w} / \mathrm{w})$ PLA in dichloromethane (DCM) containing small amount of nile red and the continuous phase was $5 \%(\mathrm{w} / \mathrm{w})$ poly(vinyl alcohol) in milli-Q water. The two immiscible liquids were introduced from the two ends of the same square capillary in opposite directions and both liquids were collected and exit through the inner circular capillary. The disperse phase was hydrodynamically flow focused by the continuous phase in the tapered section of the circular capillary, which caused the disperse phase to break into drops inside the collection tube. PLA particles were formed by DCM evaporation at room temperature. In order to prevent wetting of the collection tube with the disperse phase, the hydrophilicity of the glass surface was enhanced by 2-[methoxy(polyethyleneoxy)propyl]trimethoxysilane. Experimentally, we show that the droplet size is influenced by the operating conditions and orifice size, as shown in Fig. 1. The drop formation occurs near the orifice in the dripping regime (Fig. 1a-b) and farther downstream in the jetting regime (Fig. 1c). The drops formed in the jetting regime are significantly bigger than those formed in the dripping regime and have a broader size distribution.

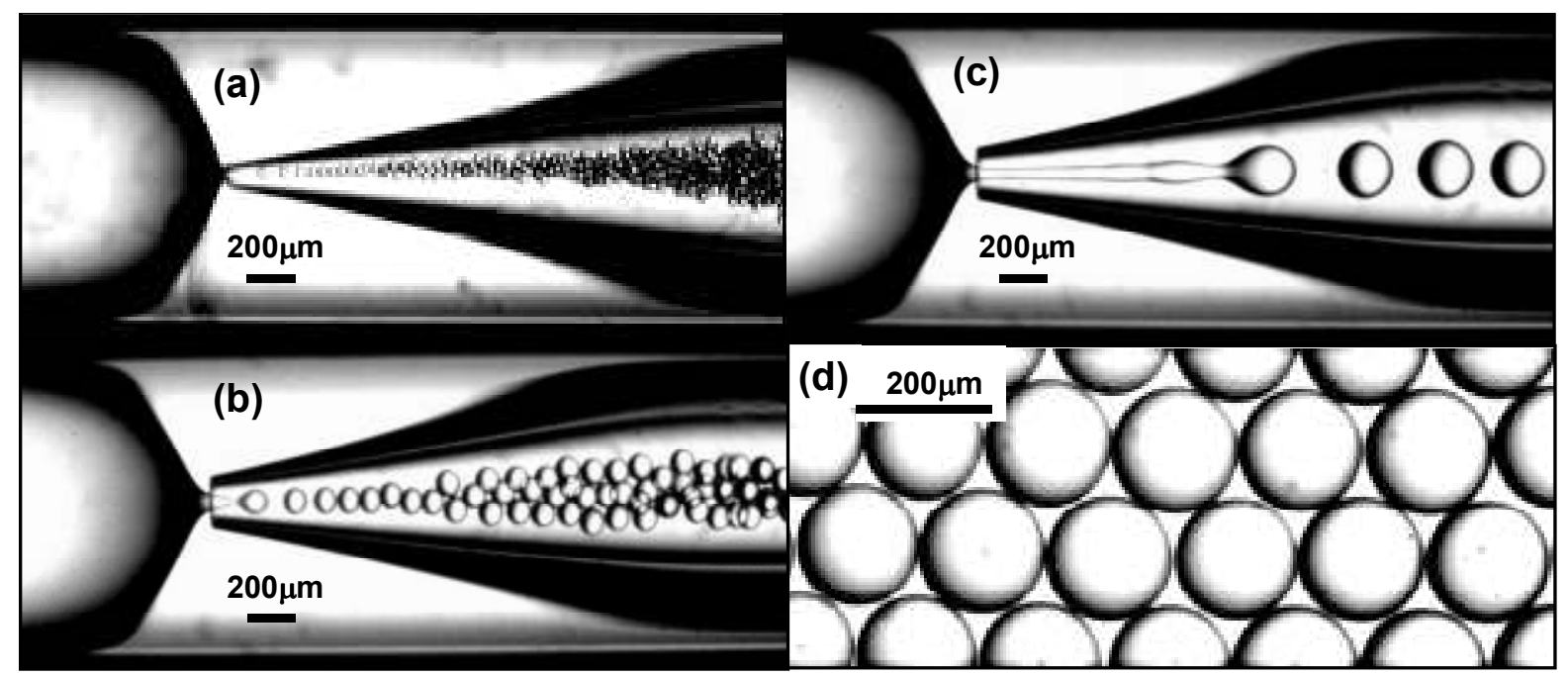

Fig. 1. (a) $Q_{c}=0.5 \mathrm{~mL} \mathrm{~h} h^{-1}, Q_{d}=0.003 \mathrm{~mL} \mathrm{~h}^{-1}, d_{\text {orifice }}=60 \mu \mathrm{m}, d_{\text {droplet }}=33 \mu \mathrm{m}$. (b) $Q_{c}=5$ $\mathrm{mL} \mathrm{h} \mathrm{h}^{-1}, Q_{d}=1 \mathrm{~mL} \mathrm{~h} \mathrm{~h}^{-1}, d_{\text {orifice }}=130 \mu \mathrm{m}, d_{\text {droplet }}=100 \mu \mathrm{m}$. (c) $Q_{c}=6.5 \mathrm{~mL} \mathrm{~h} \mathrm{~h}^{-1}, Q_{d}=0.7 \mathrm{~mL}$ $h^{-1}, d_{\text {orifice }}=130 \mu \mathrm{m}, d_{\text {droplet }}=230 \mu \mathrm{m}$. (d) Collected monodispersed droplets.

\section{Acknowledgment}

The work was supported by the Engineering and Physical Sciences Research Council (EPSRC) of the United Kingdom (grant reference number: EP/HO29923/1). 